\title{
LA CELDA, EL HÁBITO Y LA EVASIÓN EPISTOLAR EN SOR JUANA INÉS DE LA CRUZ
}

\author{
Luz Ángela Martínez \\ Universidad de Chile \\ luzmartine@gmail.com
}

RESUMEN / ABSTRACT

Centrado en las representaciones plásticas de Sor Juana Inés de la Cruz, el presente trabajo reflexiona sobre la relación entre la representación del Barroco de Indias y su contexto de producción. A partir de las anteriores coordenadas, revisa la obra de la monja y la orientación epistolar que adquieren sus poemas como forma de evasión de la celda y el hábito.

Palabras Clave: poesía virreinal, Sor Juana Inés de la Cruz, retratos, carta.

Focused on the visual representations of Sor Juana Inés de la Cruz, this paper reflects on the relationship between the Baroque of the Indies aesthetics and their context o production. Based on the above coordinates, it reviews the nun's work and the epistolary orientation that her poems acquire as a form of escape from the convent and habit.

KEY WORDS: Colonial or Viceregal Poetry, Sor Juana Inés de la Cruz, portraits, letters.

En las sociedades fundadas y organizadas según las orientaciones políticas, ideológicas y operatorias del panóptico es común que las representaciones carcelarias aparezcan más o menos disimuladas por desplazamientos, eufemismos o cadenas metafóricas en los distintos tipos de discursos producidos en ellas. Asimismo es habitual que las imágenes de la celda y el cautiverio proliferen alegórica y metonímicamente en el orden simbólico de las creaciones estéticas. De esta manera los discursos comunes y los discursos del arte, aparentemente instalados en esferas culturales distintas y/o distantes, 
generan sistemas de intercambio cimentados en un sustrato elusivo común $\mathrm{y}$ en un repertorio intercambiable de mecanismos y estrategias para "hablar ante y entre las fisuras de la Ley".

En tal contexto de producción y en necesario acomodo con el estado de vigilancia y su doble enfoque sobre lo social-corporal y simbólico-figurativo, se aprecia que la cautela, la simulación y el juego de las apariencias funcionan como dispositivos de regulación "porosos", ambivalentes y tensos, que permiten tanto como determinan las (auto)representaciones de los sujetos emisores de los discursos y las de los creadores de las diversas expresiones artísticas. Un sistema representativo orientado por tales mecanismos no solo trasluce un campo de intersecciones en constante negociación y sostenido por pactos más o menos perecederos entre la vigilancia y las necesidades expresivas del imaginario plástico y/o poético, además revela dos aspectos significativos para la producción estética: a) que la operatoria simulación-disimulación crea el espacio intersticial donde se configura la posibilidad de la representación; en este sentido, b) que esa operatoria es conatural de la imagen.

Nuestra Colonia ${ }^{1}$ en su conjunto es un excelente ejemplo de sociedad vigilada (Foucault 1979) o sociedad cerrada ${ }^{2}$, así como sus desarrollos culturales son modélicos de los vínculos entre las formas del poder, la estética y los distintos mecanismos de enmascaramiento y simulacióndisimulación que operan en los discursos. Si bien esta no es la ocasión para ahondar en los desiguales grados de subyugación experimentados por los sujetos pertenecientes a la mosaica sociedad colonial, sí es importante tener presente esa situación, en tanto los asuntos que voy a desarrollar focalizan las relaciones entre las representaciones plásticas de Sor Juana Inés de la Cruz y su creación poética, ambos aspectos especialmente intervenidos $-\mathrm{O}$

$1 \quad$ Ver la Ordenaza del 20 de febrero de 1493 del Almirante Cristóbal Colón.

En su clásico libro sobre Sor Juana Inés de la Cruz, Octavio Paz discurre largamente sobre las condiciones y características de la sociedad colonial de Nueva España. Precisamente, cuando revisa la biblioteca de la monja señala: "Si alguna sociedad mereció el nombre de Sociedad cerrada, en el sentido que Popper ha dado a esta expresión, esa sociedad fue el Imperio español. La monarquía y el clero, poseídos por una mentalidad defensiva, alzaron muros, tapiaron ventanas y cerraron todas puertas con candado y doble llave. La guardiana de las llaves fue la Compañía de Jesús" (339). La idea de "sociedad vigilada" que aquí manejo es totalmente afín a la confabulación del poder político y la ortodoxia ideológica para constituir la sociedad jerárquica que Paz advierte. 
modelados, en sentido plástico-por las normativas sociales que la llevaron a asumir el hábito de monja y a optar por la celda como lugar de habitación.

El espacio físico y el repertorio gestual (bastante limitados; más bien icónicos) con que sor Juana fue representada por el imaginario plástico colonial $^{3}$, sin duda fijaron para la posteridad una imagen suya indisociable del claustro-hábito al que la sociedad colonial del siglo XVII destinó a

3 El frontispicio dibujado por Lucas de Valdés y grabado por Gregorio Fosman para la edición sevillana de 1692 del segundo volumen de las obras de Sor Juana. El retrato de Juan de Miranda de 1713, el retrato de Miguel Cabrera de 1751 y el retrato pintado por Andrés de Islas en 1772. En este trabajo aludo a los tres últimos y no forma parte de sus objetivos determinar si tuvieron un "modelo verdadero" para su ejecución, ni argumentar sobre la fecha de su ejecución. En este sentido, refiero al imaginario colonial, que es, en definitiva, el que "eternizó" la imagen de sor Juana y al sistema de copia entre unos y otros que generan un Modelo, levantado sobre el retrato "original perdido": el Modelo barroco sin original. Para este asunto, remito al mismo Paz (304-329). Por otra parte, Margo Glantz aborda el mismo asunto desde dos puntos de vista que aquí interesan: el Modelo de las mujeres virtuosas y la figura de sor Juana como Modelo insigne del "Mexicano Museo". Respecto del primero Glantz señala lo siguiente: "Insisto, una monja-poeta es un artefacto sorprendente pero peligroso: bien clasificada, puede controlarse su productividad, inscribirse en una sección especial, una galería de retratos en donde las mujeres ocupan el lugar que les corresponde como modelos de imitación: se completa así una taxonomía sobre lo femenino que tranquiliza a sus detractores $\mathrm{y}$, de paso, protege a las mujeres, si se mantiene dentro de los límites preconizados por la clasificación". Esta galería de "mujeres virtuosas" proviene de una antigua tradición que busca perpetuar el modelo femenino en el orden familiar - del mismo modo que los retratos de las Monjas Coronadas; sin embargo, Glantz avanza sobre el punto hacia el "Mexicano Museo", en cuanto la imagen de sor Juana (monja-poeta e intelectual) es generada por la sociedad colonial de Nueva España, no por su familia, en razón de que esa sociedad busca decir algo de sí misma al tiempo que controlar el "peligroso artefacto" monja-poeta. Bien advierte Glantz que la imagen de la monja ha sido constituida por una serie de fórmulas reiterativas que generaron un "estereotipo" del cual no podemos liberarnos "en el cual ella no se reconocía cabalmente" (28-30). Solo en este último punto no concuerdo con la opinión de Glantz, pues sor Juana conocía y manejaba muy bien la imbricación barroca entre poder e imagen plástica o poética, así como tenía plena conciencia de la preeminencia que adquiría el sujeto al "aparecer como Imagen" en la sociedad; de hecho, teorizó brillantemente sobre este punto en la explicación del Neptuno Alegórico. Para el tema de la representación y el poder de la imagen en el Barroco, remito al clásico libro de Werner Weisbach: El Barroco, arte de la Contrarreforma (1948). En nuestros días, esos retratos han tenido una gran difusión, pues son numerosos los libros sobre la monja que los usan de portada, como el de Paz mismo. Lo cierto es que su imagen parece haber alcanzado el estatuto de fetiche, esto, si pensamos en los afiches que hace unos años se podían adquirir en la Universidad Claustro sor Juana de la Cruz, en los cuales el rostro de la monja aparece maquillado y con los labios pintados de rojo. 
Juana de Asbaje y a tantas otras mujeres que le fueron contemporáneas ${ }^{4}$. Esta identificación radical, realizada por el artificio del arte, naturaliza y eterniza un hecho absolutamente cultural, en este caso plagado de complejidades y significaciones de diversa índole. Como sabemos por sus datos biográficos ${ }^{5}$, se trata de la muerte de una Juana, la de Asbaje -cuya verdadera aspiración era el ejercicio intelectual-, en pos de otra Juana de nombre antecedido por la condición irrevocable de "sor", , de donde surge una tercera identidad: la de autora. Coherentemente con la operatoria simulación-disimulación que señalé al inicio, en el traspaso del umbral que marca la muerte simbólica para el mundo sucede una serie de desajustes importantes de observar de manera particular. Al contrario de lo que acontece con los apellidos, en donde Asbaje es sustituido -borrado- por "de la Cruz", el significante "Juana" se preserva, de tal manera que la permanencia del significante en las tres condiciones de ser, la laica, la religiosa y la autoral, entre otras cosas, permite trazar una línea de continuidad y concebir a la autora como una realización de la primera Juana, social y legalmente anulada, y simbólicamente ausente. Tal continuidad sugiere, de un lado, la inoperancia del "dispositivo sor" en su función traslaticia hacia una nueva vida relacionada exclusivamente con la dimensión trascendente; de otro lado, en la lógica simulación-disimulación pone de relieve su carácter de "dispositivo de gestión" entre la muerte mundana y la pervivencia de la mundanidad inherente a la condición autoral y a la producción literaria. Si

\footnotetext{
Bien sabemos que en la época la condición religiosa era una forma de vida para hombres y mujeres, un "acomodo" en la sociedad, según Octavio Paz. Sin embargo, para las mujeres este "acomodo" era bastante más estrecho, en tanto para ellas la condición de "desposadas" era irrecusable, ya fuera en su dimensión terrena o trascendente. No obstante el tutelaje masculino de las dos formas del desposorio y las ideas que se tenían sobre la nula formación de las mujeres, el convento constituyó un espacio de desarrollo de una determinada cultura femenina, tal como la investigación ha venido demostrando desde los estudios de Josefina Muriel hasta este momento, en que se ha ahondado más en el tema. Paz, por ejemplo, refiere largamente la vida conventual de la clase alta y sus laxitudes cuando revisa las posibles razones que determinaron la toma de hábito de sor Juana; de nuestra parte, pensamos que en la toma de hábitos pesaron más las posibilidades ofrecidas por el convento que la ausencia de padre a la que el crítico mexicano da tanta importancia. Cfr. Muriel: Conventos de monjas de la Nueva España (1946) y Cultura femenina novohispana (1994).
}

Sus dos ingresos a la vida conventual, el primero, fallido, a la orden de las carmelitas, el segundo, a la de las jerónimas.

$6 \quad$ Me refiero al rito de ingreso al claustro en que se asumen los hábitos de monja, es decir, a la muerte simbólica para el mundo. 
en el orden del ritual la secuencia de transformaciones no culminó, como era de esperarse -o como hubiera deseado su confesor Antonio Núñez de Miranda-, con la paz espiritual inherente a la condición de monja de claustro $^{7}$, en el plano de la representación plástica y en el orden de los signos que aquí nos interesan, la "sor" plasmada en los retratos se abre a otras dimensiones y se revela como representación de representación: como un soporte personae del significante permanente(mente) vaciado -puro"Juana", que no deja de reescribir(se) en la interpretación y en la estética contemporáneas, en lo que podríamos llamar la "heráldica"8 de la actual cultura (neo)barroca latinoamericana.

Abordar las complejidades implícitas en esta condición eternizada por el imaginario visual, no por la obra de la misma Juana, requiere que realicemos un esfuerzo "desnaturalizador" de la imagen plástica", si es que queremos atender a la inconcordancia entre ella y la imagen de sí misma que sor Juana construyó en sus poemas. Sin ánimo de entrar en la larga y muchas veces desenfocada discusión sobre la fe de sor Juana ${ }^{10}$, lo que me interesa señalar aquí es que, a diferencia de lo que sucede en otros textos producidos por

$7 \quad$ En el plano histórico, el apelativo "sor" asociado a la orden de las jerónimas y no a la de las carmelitas más bien funcionó como una cuña destinada a impedir el cierre de todas las puertas que en la época sí hubieran aislado a sor Juana del mundo de las letras y el conocimiento: el matrimonio, la condición subordinada de la mujer, la pobreza de la vida conventual. Este último elemento sin duda hubiera constituido un severo impedimento para el desarrollo intelectual de sor Juana, pues no sin razón, aquellos que se han abocado a reconstruir su biblioteca aluden el costo económico de ella, así como revisan las instalaciones del convento de las jerónimas y sus relaciones con la corte. Bien se sabe que los conventos reflejaban las jerarquías económicas y sociales de la Colonia.

En el sentido en que Severo Sarduy ha trabajado este término en sus Ensayos Generales sobre el Barroco (238-239).

$9 \quad$ Este esfuerzo "desnaturalizador" no está en desacuerdo con la obra poética, pues son más que complejas las relaciones de la autora con los retratos, con su dimensión material y con su dimensión representativa. Más conflictivas con los retratos propios. Georgina Sabat de Rivers ha trabajado el tema del retrato poético en la obra de la monja y señala: "Entre las muchas tradiciones literarias que llegaron a sor Juana parece tener un lugar especial, por la cantidad que ella dedicó al tema, las composiciones de retratos" ("Sor Juana y sus retratos poéticos" 39).

10 Cuando sor Juana aborda "cuestiones de fe", lo hace desde el ejercicio político, estético o de la discusión intelectual, no desde la profesión o declaración de crencia. Paz es enfático en este punto: "No hay alusión al llamado de Dios ni a la vocación espiritual..." (157). 
monjas, sor Juana no se autorrepresenta como religiosa, pues, en sus poemas, sus hábitos de jerónima son prácticamente invisibles ${ }^{11}$.

Para indagar en el particular sentido que tiene esa invisibilidad, parece razonable revisar la significación cultural y filosófica de las palabras "hábito" y "celda" en relación con la imagen icónica de nuestra monja, asi como en relación con su poética.

Observemos que los términos "hábito" y "celda" constituyen ambos un lugar de habitación tanto como un ser-estar en los que interior y exterior son indisociables, pues se habita el espacio arquitectónico de la celda y se incorpora la dimensión material del ropaje de la misma manera que ese espacio y esa vestimenta representan una muy determinada manera de habitar-ser en el mundo. Hábito y celda configuran un "estado" al interior de la sociedad, así como socialmente expresan y representan ese "estado", en la múltiple acepción social, política y espiritual de esta palabra. En este sentido, hábito y celda no solo conforman un "ethos", sino que, además, desde su materialidad codificada, articulan un discurso sobre lo social, lo histórico y lo trascendente, sin dejar de subrayar nunca la situación de clausura o destinación de la vida del sujeto. Si revisamos el sentido que tiene el término "ethos" desde Aristóteles hasta nuestros días, encontramos que "ethos" indica una forma de vida (la que se desarrolla ritualmente al interior de la celda) tanto como una manera de ser: la que el hábito-costumbre forma (y la que la materialidad del vestido representa).

Si recurrimos al diccionario ${ }^{12}$ encontamos que la palabra "celda" define tres espacios arquitectónicos y/o emplazamientos políticos, judiciales y culturales de profunda significación social, tal y como interpretó Michel Foulcault. Una celda es simultáneamente el aposento de un preso en la cárcel, de un estudiante en un colegio o establecimiento análogo y de un religioso en su convento. Una celda o celdilla es también una "Instalación para manipular, procesar e investigar materiales irradiados", es decir, elementos contaminantes y letales ${ }^{13}$.

$11 \quad \mathrm{Al}$ respecto, Paz dice lo siguiente: "Los poemas de sor Juana tienen un carácter muy distinto y en ellos nunca se hace la menor alusión a su estado religioso. En ningún momento la autora aparece como una monja sino como una mujer libre de la clase alta, soltera a veces y otras prometida, casi siempre en trato con uno o dos galanes." (368).

12 Diccionario de la Real Academia Española (2001). De aquí en adelante, todas las definiciones extraidas del diccionario, corresponden a esta edición.

13 Refiriéndose a la situación de la mujeres, Margo Glantz dice: "Es obvia la necesidad de tenerlas perfectamente encasilladas en espacios supervisados con estrechez, donde pudieran 
El mismo diccionario define el hábito de manera acorde a la reflexión filosófica. Un hábito es un "Vestido o traje que cada persona usa según su estado, ministerio o nación", especialmente el que usan los religiosos y religiosas. Asimismo, un "modo especial de proceder o conducirse adquirido por repetición de actos iguales o semejantes, u originado por tendencias instintivas". También es un vestido que identifica a los estudiantes y a aquellos que han cometido pecado o delito público. Por último, pero no menos sugerente, un hábito es un elemento usado como instrumento de mortificación.

Las anteriores definiciones adquieren singular pertinencia cuando observamos los retratos que el imaginario barroco colonial nos dejó de sor Juana, al mismo tiempo -quierase o no- que entablan paradójicos diálogos con los rasgos y el repertorio gestual con que la representó: la juventud como un estado permanente y/o inmanente, el boato del hábito, el lujo material e intelectual de la celda, el gesto habitual de sostener la pluma entre sus manos, o de posarlas simplemente sobre un libro abierto ${ }^{14}$. La imagen modélica repetitiva expuesta por esos retratos hasta hoy provoca en el observador un estado de incertidumbre y vacilación, pues frente a ella no podemos definir si estamos ante el imaginario visual de la plástica colonial y en el margen estricto de esas coordenadas debe ser apreciada, o si los retratos mismos contituyen una suerte de documentos "históricos" ${ }^{15}$ confusamente vinculantes -como es propio del Barroco- del orden profano (la escritura, la poesía, el conocimiento) y el sacro (la celda y las connotaciones espirituales que implica).

estar aisladas, al alcance de la mano, incapaces de causar daño. Y solamente causa daño aquello que por su misma naturaleza infringe las estrictas reglas que una sociedad ha erigido como válidas para controlar todo lo que salga de su concepto de normalidad" (39).

14 Aun cuando adjudicar los retratos al Manierismo no aparece justificado, sí vale la pena registrar la impresión de Paz al observarlos. "Agrego que las jerónimas también llevaban pulseras de azabache, anillos y escarolados los hábitos, a imitación de las concepcionistas. Las escenas pintadas en los escudillos a que se refiere de la Maza, según lo atestiguan los retratos de sor Juana, son decididamente manieristas: estilización que roza la afectación y una indefinible sensualidad a un tiempo azucarada y mórbida. En el retrato de Juan de Miranda, el más antiguo que tenemos de sor Juana, ella acaricia con la mano izquierda, como si fuese un collar, las cuentas del rosario descomunal, en un gesto más galante que devoto. En ese retrato, como en el concetto poético y en la moral de la época, triunfa el principio manierista de la conjunción de opuestos" (174). En la adjudicación manierista de estos retratos, lo que Paz no observa es que, hasta hoy, el Barroco americano siempre alude, incorpora o pone en perspectiva al Manierismo sin dejar de ser plenamente Barroco.

15 En el sentido en el que una obra de arte constituye el registro de una época. 
Si referimos estos retratos al marco representacional del Barroco y sus motivos, es decir, si examinamos el imaginario barroco colonial en el marco general del s. XVII, lo primero que habría que anotar es que la condición de "eterna juventud" de la "Fénix Americana" parece invisibilizar la muerte de la mujer de 43-45 años, aproximadamente, en medio de una epidemia. Lo significativo de aquello es que la representación "borra" totalmente el paso del tiempo (su acción devastadora en los poemas metafísicos de Quevedo, como mejor ejemplo) y la osamenta barroca del siglo XVII asociada a la actividad intelectual (Vanitas) ${ }^{16}$. El hecho es que a sor Juana no la vigila la calavera alogorizada o representada por alguno de sus emblemas, como es más que habitual en la representación barroca; al contrario, ella posa sus manos elegantemente sobre un libro-saber, como si con ese gesto acariciase uno de los muchos animales domésticos que pulularan en su celda. Para apreciar la singularidad de esta actitud, basta compararla con las representaciones máximamente desasosegadas del inspirador de la orden a la que pertenece nuestra monja, san Jerónimo, en las que la asociación de la cadena libroescritura-ciencia-actividad intelectual a la calavera advierte sobre uno de los más grandes peligros que acechan el alma humana ${ }^{17}$. La diferencia entre la representación del santo y la de la monja, llama la atención sobre el espacio intersticial de posibilidad de la imagen en el ámbito colonial, para advertir ahí la presencia de la línea discursiva-argumentativa criolla-barroca, que desatiende la advertencia funesta punitiva respecto de la ciencia humana, para aunar la inmanencia de la juventud de la sujeto representada con la de

16 Entre los múltiples trabajos que se pueden consultar sobre el tema está el de Sebastián Santiago. Cotrarreforma y Barroco: lecturas iconográficas e iconológicas. Prólogo de Alonso G. De Ceballos. Madrid: Alianza 1989.

En el retrato de Miguel Cabrera, el reloj incrustado en la biblioteca de la monja es absolutamente barroco, así como el cortinaje que encubre los libros en la esquina superior izquierda de la estantería. Sin embargo, ese reloj en nada amenaza la lozanía del rostro de la monja ni la elegancia juvenil de sus manos. Por otra parte, la tela del cortinaje alarga sobre los libros los pliegues y la cadencia del elegante hábito de la monja: los vela, los oculta, aureola la biblioteca del misterio con que el Barroco impacta los sentidos y contamina la biblioteca de esa "indefinible sensualidad" de la que habla Paz.

17 El San Jerónimo escribiendo de Caravaggio (Galería Borghese, Roma, 1605), para poner solo un ejemplo. Por otra parte, José Lezama Lima ha insistido sobre la ausencia de la osamenta medieval y la presencia de la risa en el barroco americano en La expresión Americana y en sus reflexiones sobre el pintor mexicano José Guadalupe Posada (La Materia Artizada). 
América-Nuevo Mundo, concebido este continente como fuente vital de renovación material y espiritual del (viejo) mundo ${ }^{18}$. Desde esta perspectiva, la imagen de sor Juana es símbolo y metáfora del discurso argumentativoreivindicativo del Barroco Indiano, asi como es ejemplar de su operatoria simulación-disimulación.

En otro plano, la incertidumbre producida por los retratos de sor Juana emana particularmente de las autorrepresentaciones de la obra poética y sin duda de las declaraciones que la monja vertió en la famosa carta Respuesta a sor Filotea de la Cruz, las que discuten con esos registros visuales un poco posteriores, es cierto, pero propios del mismo imaginario y periodo en que fue escrita la carta. Si no olvidamos o banalizamos (que es una de las formas más eficaces del olvido) que Juana entró al claustro y confinó su existencia a la celda para poder desarrollar su actividad intelectual, de ninguna manera podemos definir si esos retratos exponen la figura de una monja o de una escritora del siglo XVII ${ }^{19}$. Este asunto bastante trillado, por el contrario se torna insoslayable si se apunta a la operatoria simulación-disimulación como elemento congénito de la imagen y mecanismo regulador del campo expresivo. Pues las luces que la carta proyecta sobre los hábitos -reales o representadosde sor Juana, inducen un efecto anamórfico que obliga al lector-observador a un desplazamiento en virtud del cual, en una misma figura, una monja se ve desmentida por el camaleónico gesto de una escritora que se ha camuflado con los hábitos -espirituales y materiales; con el ethos-de una monja. Ciertamente, a partir de aquí las definiciones llanas sobre la identidad referenciada por el significante - puro, vaciado- "sor Juana" carecen de importancia, en cuanto el movimiento anamórfico dinamiza y encabalga una nueva transformación en el ámbito de la significación histórica: la transfiguración de la imagen icónica de la monja en la imagen del Proteo ${ }^{20}$ femenino y tutelar del Barroco Americano, atrapado en una celda colonial.

18 En el acápite "Sor Juana, el oro racional", en la misma línea de Antonio Alatorre, Margo Glantz examina el proceso de metaforización del que fue -y es- objeto sor Juana y que la convirtió en "paradigma de lo americano" (36). Por su parte, Paz nos informa que el cuadro de sor Juana pintado por Juan de Miranda fue adquirido por la Universidad Nacional Autónoma de México y se encuentra en la Rectoría de esta Casa de Estudios.

19 Escritora con "celda propia", en un sentido literal.

20 Utilizo la figura de Proteo tal como la trabajó Jean Rousset en su obra Circe y el Pavo Real. La Literatura Francesa del Barroco. 
Algo parecido sucede si focalizamos la relación entre el sujeto y el mundo representado en los cuadros. Influenciados por los efectos de la metaanamorfosis que se proyecta desde la carta escrita en la Colonia hasta hoy, resulta que el lugar físico también se inserta en el mismo tejido de incertezas. Como dije, no sabemos si el espacio representado en los retratos de sor Juan es el lugar en el que una intelectual habita y desarrolla su trabajo ${ }^{21}$, o si se trata de un lugar de reclusión - una "celdilla", en el sentido que nos entrega el diccionario ${ }^{22}$-, suntuosamente equipado y disimulado por una impresionante biblioteca. Esto, sobre todo, porque esa biblioteca es un elemento tan inherente como mitificador de la escritora barroca más famosa de nuestra historia. Así como la renuncia a ella es particularmente indisociable de la persecución ortodoxa de la que fue objeto y de su muerte, en el campo cultural amplio la biblioteca colonial también conlleva el discurso argumentativo-reivindicativo del intelectual americano ${ }^{23}$. En este sentido, el "enmarque" de la imagen de la monja en medio de sus libros no solo representa plenamente lo dicho por Carlos de Sigüenza y Góngora sobre sor Juana en su Theatro de Virtudes Políticas, también recoge ideológicamente la disputa del mismo Sigüenza y la de otros criollos con la intelectualidad peninsular-europea por el saber. De tal manera que en el campo de intersecciones negociado entre la vigilancia y las posibilidades expresivas, la biblioteca-mundo(colonial), representada en los retratos de sor Juana, alegoriza el conflicto criollo-peninsular, de la misma manera que en ese campo se presenta como una "zona endurecida" o de alta tensión ${ }^{24}$. Por último, en la imagen de la biblioteca convergen con igual

21 Como sabemos, las celdas eran propiedades privadas, algunas sumamente cómodas, dotadas de dependencias para esclavas y/o criadas que se compraban y vendían desde el interior del convento. La investigación contemporánea sobre la vida conventual del s. XVII adelanta que en cierto sentido constituían espacios privilegiados de independencia femenina.

22 Con relación al significado de "celdilla", no debemos olvidar que el jesuita Antonio Núñez de Miranda, calificador del Santo Oficio, es quien gestiona el ingreso de Juana de Asbaje a la vida conventual. Sin embargo, este hecho contrasta con la impresión que causan los retratos. Hablando de las celdas de las monjas, Paz nos hace partícipes de la suyas: "la de sor Juana, a juzgar por sus retratos, era elegante y un si no es teatral" (179).

23 No son pocos los esfuerzos de la crítica contemporánea por recomponer la biblioteca de sor Juana: a partir de la revisión de los autores citados por la monja, de sus retratos y de una serie de conjeturas sobre la profundidad de su conocimiento. Este esfuerzo parece encerrar un secreto deseo de reponerle en la fama aquello que suponemos le fue arrebatado.

24 No en vano los "datos duros" sobre los libros que circulaban en las colonias se encuentran en los registros del Santo Oficio (Trabulse 125-230). 
intensidad el control inquisitorial sobre los libros que llegaban a las colonias, como la evidencia de su burla. En tal sentido, la secuencia anamórfica celdabiblioteca, resultante de la operatividad simulación-disimulación, obliga a componer la figura ambivalente y tensa de la "biblioteca enclaustrada", y a reflexionar sobre esta figura espacial en relación con la producción plástica colonial y con la producción poética de nuestra autora.

Ahora bien, en el visible/invisible hábito barroco de sor Juana sin duda se concentra la operatoria simulación-disimulación. Sobre todo si buscamos interpretar el hábito como un símbolo exterior de la actividad espiritual, o como la forma visible de la persona interior; es decir, si pretendemos responder a las siguientes preguntas: ¿Cuál es la actividad espiritual que simboliza ese hábito en particular? ¿Cuál es la persona interior que visibiliza? Aquí también es imposible definir si la lujosa vestimenta expresa el poder económico y el prestigio adquirido (otra forma del poder) por la intelectual que la ostenta ${ }^{25}$, o si esas sedas y damascos son un refinadísimo vestido de presidio, de mortificación. En este caso, la indeterminación y/o posibilidad anamórfica convoca las operatorias del disfraz y la máscara para señalarlas como la actividad espiritual verdaderamente simbolizada por el hábito, de tal manera que ese hábito (en sus varias acepciones) se convierte más bien en el símbolo de una travestización ${ }^{26}$ acaecida simultáneamente en distintos niveles: el intelectual, el material y el espiritual. Sin embargo, como aquí el hábito no hace a la monja -o no nos perite definirla-, lo que importa es que ese hábito barroco configura el escenario una metamorfosis en suceso que bascula entre el significante puro "Juana" y el soporte personae "sor Juana", aprehensible solo como "Imagen", en el sentido poético que le dio a este concepto José Lezama Lima en su obra ensayística (vgr., El reino de la imagen $)^{27}$. Por otra parte, lo que sí queda claro, es que la metamorfosis en suceso constituye la

25 Esta ostentación también debe considerarse como un elemento ideológico de la plástica colonial, que disimula su discurso con el boato permitido; en palabras de José Lezama Lima, "con fastuosidad que cruje en el misal."

26 Tal y como ha sido interpretado, por ejemplo, por Mabel Moraña en Viaje al Silencio. Exploraciones del discurso barroco. Diccionario de la Real Academia Española: Travestismo: Práctica consistente en la ocultación de la verdadera apariencia de alguien o algo. U. t. en sent. fig.

27 Lezama, que nos habla del Rey-Poeta y de su poder cohesivo y reformulador de las épocas históricas, desafortunadamente no se detiene lo suficiente para percatarse que en el ámbito americano la imagen de sor Juana tiene esas características. 
contracifra de las claves penitenciarias de la sociedad colonial que habitó aquella que en el siglo se llamó Juana Ramírez de Asbaje, Sor Juana Inés de la Cruz, Décima Musa, Fénix de América y La peor del mundo.

Ahora bien, si sor Juana no se autorrepresenta como una monja, ¿cómo se manifiestan la celda y el hábito en los textos?

Antes de atraer algunos de los poemas en los cuales sor Juana alude a su condición de encierro, resulta importante detenerse en un aspecto que nos puede iluminar las relaciones entre su escritura y la sociedad panóptica en la que la produjo. Para ello remito nuevamente a la carta Respuesta a sor Filotea de la Cruz, ya no por los datos biográficos que entrega, sino para sugerir su pertenencia genérica y su específica función comunicativa como dos elementos caracterizadores de la obra de sor Juana.

En tanto producción poética realizada totalmente en el encierro, más allá de esa reducida parte de su obra clasificada bajo el rótulo "epistolar" ${ }^{28}$, en gran medida la obra de sor Juana tiene la forma de un diálogo escrito o de un epistolario poético, en el cual sus poemas adquieren la función de una carta respuesta a algún asunto concreto que se le pide o demanda desde el exterior. Pruebas de ello son los "poemas misiva" en los que agradece un regalo o acompañan otro que ella misma envía fuera del claustro y que de su parte refieren a asuntos tan domésticos como la factura de una conserva; o aquellos en los que responde sobre preceptos musicales a una de sus amigas; o aquellos otros en los que, por medio de la formalidad de la carta, expresa la voluntad de figurar e interferir en lo político-público, cuando dirige peticiones poéticas de orden social o judicial a la autoridad.

Como bien se sabe, la carta Respuesta a sor Filotea no es ni el primero ni el único texto en el cual sor Juana contesta un ataque. Por el mismo medio, pero ya en una dimensión poética, replica las agresiones que le hacen extramuros, tal como muestra ejemplarmente aquel poema con el que responde la insolencia de un caballero del Perú que le dice que se convierta en hombre ${ }^{29}$. Con la misma fórmula poético-epistolar, sor Juana realiza peticiones personales que le son importantes; recordemos aquel poema dirigido a su querido don Payo para solicitarle el sacramento de la

28 Trece en total son los poemas clasificados como "Romances Epistolares".

29 En el mismo sentido y tono se encuentra el epigrama comentado por Georgina Sabat de Rivers, del cual comenta esta crítica “...en buen español, lo que hace la poeta es llamar al que la ha atacado, "hijo de puta", (En busca 40). 
confirmación, cuyo encabezado es ni más ni menos que el de una carta. El primero de los poemas al que me refiero, clasificado como Romance Epistolar en las Obras Completas ${ }^{30}$, comienza así:

Señor: para responderos... (62)

El segundo, igualmente clasificado, pero de sentimientos totalmente opuestos, mantiene el mismo encabezado epistolar:

\author{
Ilustrísimo Don Payo, \\ amado Prelado mío; \\ y advertid, Señor, que es de \\ posesión el genitivo: (16)
}

Fuera de estos romances epistolares canónicos, encontramos una serie de poemas en los que la monja acentúa la dimensión de la misiva para tratar asuntos puntuales; generalmente, cuando se refiere o comenta la obra de otros autores. Por ejemplo:

Tulio Español: mal al veros

$$
\text { (...)" (117) }
$$

En otras ocasiones, el poema no tiene el encabezado de la carta, pero es un texto escrito para tratar-porfiada y precisamente- un asunto no perteneciente a la órbita de lo personal pero sí de su interés. Como podemos presumir al leer "Memorial a un Juez", la monja ya ha dirigido reiteradas poemas-misivas a su destinatario para abogar por la causa de una viuda:

$$
\begin{aligned}
& \text { Juzgo, aunque os canse mi trato, } \\
& \text { que no os ofendo, en rigor, } \\
& \text { pues en cansaros, Señor, } \\
& \text { cumplo con vuestro mandato; } \\
& \text { y pues éste fue el contrato, } \\
& \text { sufrid mis necias porfías } \\
& \text { de escuchar todos los días } \\
& \text { tan continuas peticiones, }
\end{aligned}
$$

30 Todos los poemas citados o aludidos pertenecen a esta edición y serán citados con el número de página en donde aparecen. 
que aquestas mis Rogaciones

se han vuelto ya Letanías.

$(\ldots) "(121)$

Como cualquier escritor profesional, vía el poema-carta, sor Juana trata asuntos de dinero. Esta función pragmática-comunicativa, económica, casi de recibo- constituye el asunto del poema en el que agradece -ambiguamenteel pago que recibió del Cabildo de México por la realización del Arco de Triunfo erigido en honor del virrey Marquéz de la Laguna.

Esta grandeza que usa

conmigo vuestra grandeza, le está bien a mi pobreza pero muy mal a mi Musa. Perdonadme si, confusa o sospechosa, me inquieta el juzgar que ha sido treta la que vuestro juicio trata, pues quien me da tanta plata no me quiere ver Poeta (120).

No obstante todos los poemas anteriores muestran que la escritura fue para sor Juana un vehículo eficaz para traspasar los muros del convento, hay un poema -clasificado en la Obras Completas bajo el rótulo "Billetes y Otros Poemitas"- en que queda clara la función comunicativa de la obra de sor Juana. Como se verá inmediatamente, ahí se alude a la materialidad del mensaje y a su intercambio habitual, al carácter "secreto" e íntimo que lo envuelve y a su forma de circulación:

El paje, os dirá, discreto, cómo, luego que leí, vuestro secreto rompí para no romper el secreto. Y aun hice más, os prometo: los fragmentos, sin desdén, del papel, tragé también; que secretos que venero, aun en pedazos no quiero que fuera del pecho estén (119). 
Los anteriores ejemplos revelan que la obra misma también exhibe operaciones complejas acordes a la anamorfosis que hemos señalado, en tanto la función comunicativa y la expresiva-estética se mixturan y el poema se transfigura en una carta o al revés.

Si bien los poemas-carta son medios efectivos a través de los cuales sor Juana rompe el aislamiento de la celda y trasciende el hábito para entablar diálogos no siempre felices con la sociedad, en otro orden constituyen una especial forma de documento o manifiesto cuya afortunada conservación nos permite conocer los conflictos ideológicos y las relaciones sociales que suscitaron su escritura. Por eso mismo llaman la atención sobre el despliegue de la escritura poética como estrategia comunicativa en la sociedad panóptica. En este último sentido, estos poemas-carta deben ser observados como textos híbridos que cumplen una función muy específica de "representación", en uno de los sentidos que la RAE da a esta palabra: "sustituir a alguien o hacer sus veces, desempeñar su función o la de una entidad", pues los poemas-carta "representan" a la enclaustrada (informan, declaran, rebaten o refirieren), así como configuran una especial forma de "presencia estética" por medio de la cual la famosa escritora Sor Juana Inés de la Cruz figura y se representa (en el sentido dramático del término) como tal en la sociedad ${ }^{31}$.

Si el avance de lo epistolar hacia lo público proporciona un productivo punto de vista para exponer las estrategias evasivas del claustro-hábito, lo que los poemas-carta muestran en el ámbito de la intimidad resulta todavía más significativo, pues una lectura extendida de la obra de la monja revela una plena conciencia de funcionalizar sus poemas como cartas, respuestas, apelaciones o medios en general para mantener diálogos íntimos en el orden de los afectos. En ellos, más de una vez la escritura poética misma marca la condición epistolar-comunicativa- del poema, en cuanto se hace referencia directa al diálogo diferido que mantiene con alguna de sus amigas las virreinas. Esto se observa claramente a propósito de reclamos propios de la amistad y en relación con "las prisiones del retiro", cuando la monja le dice a una de las virreina frases tales como "te escribo" (poema 17, p. 24) o "no quise escribirte" (poema 18, p. 25) en el poema que se le envía o

31 Al comentar la actividad escritural de sor Juana, Paz se lamenta por la pérdida de su nutrida correspondencia y acota: "Además de su obra literaria, nada desdeñable por la cantidad y por la diversidad de asuntos, fue una infatigable escritora de cartas". Y un poco más adelante agrega, "la avidez de sor Juana por la comunicación escrita revela cierto oportunismo, un ansia inmoderada por conocer y ser conocida. Vanidad, sí, pero asimismo soledad" (180-181). 
dedica. Esa afirmación íntima epistolar del poema, marcada por la primera y segunda persona del singular, nos informa del mundo psíquico y emocional de la monja, de la intensidad de sus afectos, deseos y frustraciones, así como de los vínculos amorosos que mantuvo extra muros del claustro y que tanto han dado que hablar a los exegetas de su obra.

No hay duda de que podríamos examinar largamente la interioridad de sor Juana a través de la condición epistolar de sus poemas, sin embargo, en esta ocasión dejo de lado ese interesantísimo aspecto para hacerme cargo de la forma particular que adquieren los textos en relación con las condiciones sociales de su producción. En este sentido, es necesario preguntarse por qué los poemas de sor Juana adquieren la forma de la carta y cumplen su misma función comunicativa. Como es de esperarse, la única respuesta válida a nuestra pregunta se encuentra en los mismos poemas.

Precisamente en un poema dirigido a su amiga, la condesa de Galve, sor Juana hace explícita queja por su situación de encierro. De entre los muchos poemas en que sor Juana alude con mayor o menor profundidad al asunto, elijo este para hacer presente que esa queja es relevante para comprender aspectos de su poética. Significativamente, en este texto la voz enunciante se identifica ontológicamente con el angustiado discurso de Segismundo de La vida es sueño de Calderón de la Barca, cuando este personaje eleva su queja y expresa su rabia entristecida por su inexplicable reclusión. Tal como el personaje dramático, en el texto de la monja la voz poética reclama con justicia esencial su pertenencia al género humano, para derivar de aquella pertenencia su derecho (natural) a la libertad.

\footnotetext{
¿Nací yo acaso en las yerbas, o críeme en las ortigas?

¿Fue mi ascendiente algún risco, o mi cuna alguna sima?

¿No soy yo gente? ¿No es forma racional la que me anima? ¿No desciendo, como todos, de Adán por mi recta línea? ${ }^{32}$
}

32 Probablemente aquí podemos encontrar un eco de las discusiones sobre la pertenencia o no del indígena a la genealogía adánica, es decir, sobre si tenía alma o no. 
Este reclamo de humanidad basado en el libre albedrío involucra lo trascendente para focalizarse luego en el alegato por las libertades individuales del sujeto, las que en el orden histórico están reguladas y restringidas por los poderes políticos e ideológicos que rigen la sociedad. Primero veamos que en sor Juana la protesta es por el encierro físico concreto; luego, que la justa demanda configura una paradoja poética y vital sin resolución a lo largo de su vida y obra, porque el encierro ante el cual se rebela, posteriormente es afirmado como la única forma posible de existencia en su sociedad, tal como confirma décadas después el registro biográfico de la Respuesta a sor Filotea.

Lo primero, el encierro concreto:

Pues por qué no he de ir a verte

cuando todos te visitan?

¿Soy ave nocturna para

no poder andar de día?

Si porque estoy encerrada

me tienes por impedida,

para estos impedimentos

tiene el afecto limas.

La paradoja se desprende también de la operatoria simulación-disimulación que con sus múltiples juegos establece la diferencia entre Segismundo (entendiendo, por supuesto, al personaje como una reflexión y una propuesta libertaria citadas por la monja) y sor Juana, pues el personaje dramático asume el juego de las apariencias como estrategia para salir de su encierro y vivir en la sociedad. La monja, por el contrario, lúcidamente percibe la imposibilidad de la libertad en una sociedad carcelaria que idea formas simbólicas de lo monstruoso como fórmula de control. Así lo dice en el poema en que responde al caballero que le escribió el romance "Madre que haces chiquitos" (poema 49):

¡Qué dieran los saltimbancos,

a poder, por agarrarme

y llevarme, como Monstruo,

en esos andurriales

....

¡Aquesto no! No os veréis

en ese Fénix, bergantes; 
que por eso está encerrado

bajo treinta llaves (66).

Queda claro que el asunto de la libertad no se resuelve para sor Juana con el hecho de habitar fuera de la celda, en la sociedad. Más bien se define y cobra toda su profundidad en contradicción con los principios penitenciarios que animan la normativa social en lo más medular. Ahora, si tal normativa opera en el imaginario social y desde ahí impone la deshumanización de la sujeto en la categoría de lo monstruoso-aberrante, en el orden de la subjetividad desata el imaginario de la autoaniquilación:

¿Qué mi tintero es la hoguera

Donde tengo que quemarme,

Supliendo los algodones

Por Aromas Orientales?

Frente a la monstruosidad o la hoguera, la paradoja del "autoencierro libertario" se presenta como un acto de autodefensa y de huída. En consecuencia, no sorprende que en la poética de sor Juana la imagen mítica y trágica de Ícaro -el "emplumado" que se "incendia" en su fuga libertaria, como sor Juana, figurada por su pluma, se "quema" en su tintero- sea el doble correspondiente de la de Segismundo.

Al inicio de este trabajo afirmé que los estados de vigilancia apuntan simultáneamente a lo social y lo corporal y que esto determina significativamente las autorrepresentaciones de los sujetos en los discursos y sus representaciones en las obras de arte. Conviene, entonces, hacer una breve referencia a la representación y autorrepresentación del cuerpo en algunos poemas de sor Juana.

La representación o la ausencia de lo corporal constituye uno de los aspectos más interesantes de la poesía de sor Juana y sin duda amerita un análisis exclusivo porque no se resuelve solamente aludiendo a su condición monjil. Pero por el momento me interesa tratar la neutralización del cuerpo encerrado, a partir de la cual se articula la supremacía de la actividad mental y sicológica como vía de realización de todos los deseos y anhelos de la afectividad.

Primero observemos la desaparición o escamoteo de la materialidad (sexualidad) del cuerpo mediante el recurso al género neutro del latín que tan bien conoce desde niña. En el ya citado poema-respuesta "al caballero del Perú que le envió unos barros diciéndole que se volviera hombre", sin dejar de marcar distancia del mito de Sálmacis y Hermafrodito - que sin duda remite a una "neutralidad sexuada"-, sor Juana toca el tema de su propia 
sexualidad y la define en un tercer término o categoría ajena a la bipolaridad masculino/femenino:

Yo no entiendo de esas cosas;

solo sé que aquí me vine ${ }^{33}$,

porque, si es que soy mujer,

ninguno lo verifique

Y también sé que, en latín,

solo a las casadas dicen

úxor, o mujer, y que

es común de dos lo Virgen.

(...)

y solo sé que mi cuerpo,

sin que a uno u otro se incline,

es neutro, o abstracto, cuanto

sólo el Alma deposite.

Entre las paredes físicas de la "biblioteca encarcelada" -a la cual remito al resaltar la declaración "aquí me vine" en el poema-, el cuerpo encerrado sufre una suerte de metamorfosis que lo convierte en un cuerpo-letra abstracto, cuya materialidad sexuada desaparece - o se fuga- en una neutralidad conceptual, tan codificada por la lengua como inasible en lo concreto. De tal manera que ahí, en ese lugar, entre cuerpo y biblioteca se produce una alineación mimética extrema y una particular transferencia por la cual el cuerpo es signo entre los signos, significante sin polaridad.

No obstante la radicalidad del proceso, la abstracción no significa la anulación de la actividad emocional; muy por el contrario, ésta va a buscar su realización por otras vías. Así se anuncia, por ejemplo, en aquel poema dedicado a la condesa de Galve que ya cité, en el cual observamos un "deseo tránsfuga" -"emplumado", sin duda "icarizado"- que se escapa por los muros, para configurar otra forma de vivir la libertad coartada física y socialmente:

Sutil y ágil el deseo,

no hay, cuando sus plumas gira,

solidez que no penetre

ni distancia que no mida.

33 Las negritas son mías. El "aquí,, sin duda remite al claustro, encabalgado semáticamente con el hábito. 
Como es de esperar, la abstracción del propio cuerpo es solo una parte de un proceso mayor que contempla la abstracción del cuerpo del otro. Remitámonos a aquel magnífico poema que se conoce como "Que contiene una fantasía contenta con amor decente" (poema 165), en el cual se subvierte el signo negativo de la cárcel y la abstracción toma otros rumbos para que el deseo amoroso se resuelva por la vía de la sublimación; esto es, por medio de la encarcelación de la imagen del cuerpo ajeno. Observemos la sublimación:

Detente sombra de mi bien esquivo, imagen del hechizo que más quiero, bella ilusión por quien alegra muero, dulce ficción por quien penosa vivo.

Ahora la encarcelación de la imagen:

Mas blasonar no puedes, satisfecho, de que triunfa de mí tu tiranía:

que aunque dejas burlado el lazo estrecho

que tu forma fantástica ceñía, poco importa burlar brazos y pecho si te labra prisión mi fantasía (43).

Bien podemos ver en este poema una magnificación del motivo del aprisionamiento en el cual confluye la imagen de la cárcel manierista y barroca, pero como sucede invariablemente en la poética de sor Juana, la representación modélica va a ser desencajada y conducida a un nuevo ámbito de significación. En este caso sucede que el lugar por excelencia de la represión es resignificado por la hablante del poema, y la cárcel misma va a ser el lugar de la libre realización: del ejercicio intelectual, del deseo y del impulso amoroso, de tal manera que la celda se nos revela como el lugar de realización de la "intensa erótica imaginaria" de sor Juana, de la que habla Paz.

\section{BIBLIOGRAFÍA}

Aristóteles. Ética a Nicómaco. Buenos Aires: Gradifco, 2008.

Colón, Cristóbal. Textos y documentos completos. Relaciones de viajes, cartas y memoriales.

Ed. Consuelo Varela. Madrid: Alianza, 1982. 
Cordón López, Victoria. "La fortuna de escribir: escritoras de los siglos XVII y XVIII". Historia de las mujeres en España y América latina II. Coord. Isabel Morant. Madrid: Cátedra, 2005.

Cruz, sor Juana Inés de la. Obras completas. México: Porrúa, 2004.

Foucault, Michel. Vigilar y castigar: nacimiento de la prisión. Trad. Aurelio Garzón del Camino. Madrid: Siglo XXI, 1979.

Glantz, Margo. Sor Juana Inés de la Cruz: ¿Hagiografia o Autobiografia? México: Grijalbo, 1995.

Lezama Lima, José. El reino de la imagen. Caracas: Biblioteca Ayacucho, 1981. La expresión Americana. México: Fondo de Cultura Económica, 1993. La Materia Artizada. Madrid: Tecnos, 1996

Morales Toro, Leonidas. La escritura de al lado: géneros referenciales. Santiago: Cuarto Propio, 2001.

Moraña, Mabel. Viaje al Silencio. Exploraciones del discurso barroco. México: Universidad Nacional Autónoma de México, Facultad de Filosofía y Letras, 1998.

Muriel, Josefina. Conventos de monjas de la Nueva España. México: Editorial Santiago, 1946. Cultura femenina novohispana. México: UNAM, 1994.

Paz, Octavio. Sor Juana Inés de la Cruz o Las trampas de la fe. Barcelona: Seix Barral, 1982.

Rousset, Jean. Circe y el Pavo Real. La Literatura Francesa del Barroco. Traducción de Jordi Marfá. Barcelona: Seix Barral, 1972.

Sabat de Rivers, Georgina. En busca de sor Juana. México: Facultad de Filosofía y Letras (UNAM) 1998. “Sor Juana y sus retratos poéticos". Revista Chilena de Literatura. 23 (1984): 39-52.

Sarduy, Severo. Ensayos Generales sobre el Barroco. Buenos Aires: Fondo de Cultura Económica, 1987.

Sigüenza y Góngora, Carlos de. Seis obras. Ed. William G. Bryant. Caracas: Biblioteca Ayacucho, 1984.

Trabulse, Elías. Ciencia y Religión en el Siglo XVII. México: El Colegio de México, 1974.

Weisbach, Werner. El Barroco, arte de la Contrarreforma. Madrid: Espasa-Calpe, 1948. 